\section{A very unusual appearance of a rare endoscopic finding: esophageal hematoma}

A 45-year-old woman presented with severe odynophagia, epigastric pain, and hematemesis 5 hours after ingesting dried hard squid and having had difficulty swallowing the food bolus. Upon presentation, she was hemodynamically stable with hemoglobin $11.7 \mathrm{~g} / \mathrm{dL}$, platelet count $178 \times 10^{9} / \mathrm{L}$, and an INR of 1.1. Endoscopy showed a large, longitudinal, submucosal esophageal hematoma extending from $15 \mathrm{~cm}$ past the incisors to the distal esophagus ( $\bullet$ Fig. 1 and 2 ). The hematoma resembled a single varix surrounded by whitish mucosa with visible blood flow within the column. The patient was treated conservatively and discharged after 2 days. Repeat endoscopy 1 month later showed complete resolution of the hematoma ( $\bullet$ Fig. 3).

Esophageal hematoma is a rare endoscopic finding and can result from iatrogenic complications of instrumentation such as endoscopy, sclerotherapy for esophageal varices, esophageal stricture dilation, esophageal biopsy, transesophageal echocardiography, or prolonged nasogastric tube placement [1]. It can also result from trauma induced by foreign bodies or hard food boluses (e.g., tortilla chip, fish/chicken bone). Spontaneous esophageal hematoma may occur and is thought to be due to episodes of sudden changes in transmural pressure such as in protracted coughing or retching, especially in patients with abnormal hemostasis [2].

Patients may present with nonspecific complaints mimicking cardiovascular, pulmonary, or esophageal disease. Typical symptoms include chest pain, dysphagia/odynophagia, and/or hematemesis. The differential diagnosis includes aortic dissection, acute myocardial infarction, esophageal perforation, Mallory-Weiss tear, peptic ulcer disease, and esophageal cancer. Early diagnosis is crucial, as misdiagnosis may result in the use of anticoagulation therapy in cases of suspected myocardial infarction, leading to catastrophic bleeding [3]. Findings on endoscopy include esophageal mucosal discoloration and swelling, which can be confused with esophageal varices, tumor, or aortoesophageal fistula. Esophageal he-

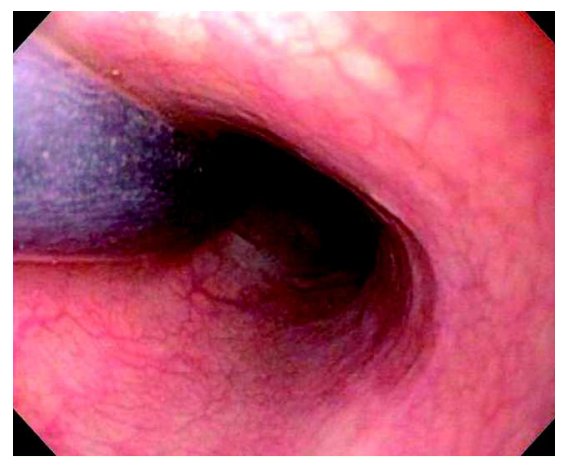

Fig. 1 Esophageal hematoma as it appears in the mid esophagus.

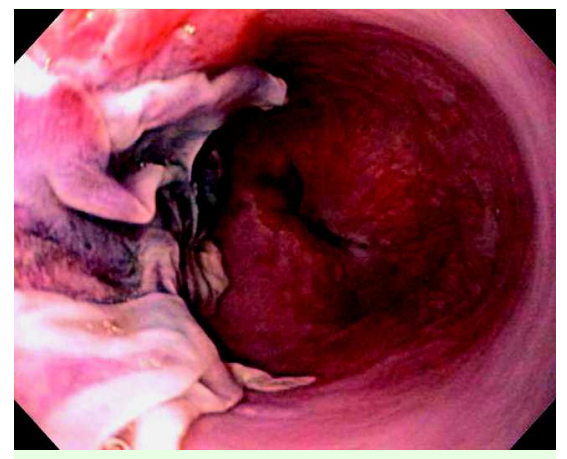

Fig. 2 Esophageal hematoma as it appears in the distal esophagus.

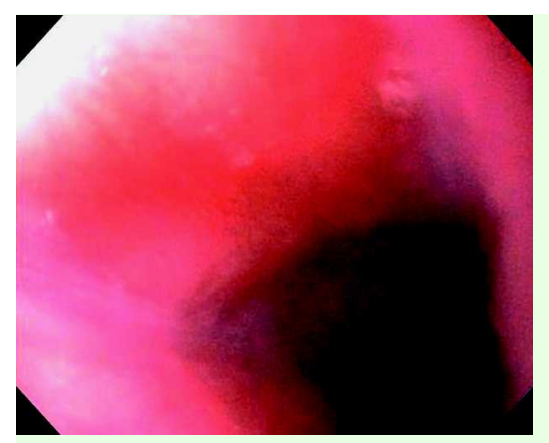

Fig. 3 One month following initial endoscopy: resolution of esophageal hematoma.

matomas should be treated conservatively with the patient receiving nothing by mouth, intravenous fluids, and intravenously administered antibiotics if necessary. Most patients will fully recover without long-term complications [4].

Endoscopy_UCTN_Code_CCL_1AB_2AC_3AG

\section{A. W. Lin, M. Eng, D. Robbins}

Beth Israel Medical Center, Division of Digestive Diseases, New York, New York, USA

\section{References}

1 Younes Z, Johnson D. The spectrum of spontaneous and iatrogenic esophageal injury: perforations, Mallory-Weiss tears and hematomas. J Clin Gastroenterol 1999; 29: 306-317

2 Jotte RS. Esophageal apoplexy: case report, review, and comparison with other esophageal disorders. J Emerg Med 1991; 9: 437 443

3 Cullen SN, Chapman RW. Dissecting intramural hematoma of the oesophagus exacerbated by heparin therapy. QJM 1999; 92: $123-124$

4 Barone JE, Robiloti JG, Comer JV. Conservative treatment of spontaneous intramural perforation (or intramural hematoma) of the esophagus. Am J Gastroenterol 1980; 74: $165-167$

\section{Bibliography}

DOI $10.1055 / \mathrm{s}-0028-1119458$

Endoscopy 2009; 41: E40

(c) Georg Thieme Verlag KG Stuttgart · New York . ISSN 0013-726X

\section{Corresponding author}

\section{A. W. Lin, MD}

Beth Israel Medical Center, Division of Digestive Diseases 350 E. 17th Street

New York

NY 10003

USA

Fax: (1)212-420-4373

lin.amy.w@gmail.com

\section{Video 1}

Findings on initial endoscopy. 